\title{
An Evaluation Study on the 1st-Grade Junior High Schools' English Textbook in the Light of Multiple Intelligence Theory
}

\author{
Elham Kia-Ahmadi ${ }^{1} \&$ Ali Arabmofrad ${ }^{2, *}$ \\ ${ }^{1}$ Department of English Language Teaching, Golestan Science and Research Branch, Islamic Azad University, \\ Gorgan, Iran \& Department of English Language Teaching, Gorgan Branch, Islamic Azad University, Gorgan, Iran \\ ${ }^{2}$ Department of English Language and Literature, Golestan University, Gorgan, Iran \\ *Corresponding author: Department of English Language Teaching and Literature, Golestan University, Iran. E-mail: \\ a.arabmofrad@gu.ac.ir
}

Received: December 10, 2014 Accepted: January 6, 2015 Online Published: January 21, 2015

doi:10.5430/wjel.v5n1p23

URL: http://dx.doi.org/10.5430/wjel.v5n1p23

\begin{abstract}
The present study aimed to explore the level of Gardner's (1993) multiple intelligences theory in the 1st- grade junior high school textbook "Prospect 1". To this end, 135 Iranian learners of 1st-grade junior high schools were assigned from public, private, and gifted schools in three different cities in Iran. The data was collected through a 50-item multiple intelligence checklist extracted from Bottelho's (2003) multiple intelligence evaluation checklist in order to count the catered-for types of intelligences in the textbook. In order to analyze the data, the descriptive statistic was used. It was found that the book intelligence profile is predominantly composed of two intelligences: verbal/linguistic and visual/spatial intelligences. However, the less common intelligences were musical and naturalistic intelligences.
\end{abstract}

Keywords: multiple intelligences theory (MI); textbook evaluation

\section{Introduction}

Textbooks along with teachers, learners and context are the four important factors in the educational context (Razmjoo \& Jozaghi, 2009). According to Riazi (2003, p.52), "textbooks play a very crucial role in the realm of language teaching and learning and are considered the next important factor in the second/foreign language classroom after the teacher". The wide use of English textbook as the main source in the Iranian schools is understandable considering the fact that "textbooks are not merely the routine instruments of the language for teachers, indeed they are an embodiment of the goals, of the particular teaching/ learning circumstance" (Tomlison, 2003). Moreover, the collection of a meticulous core textbook conveys an administrative educational determination in which there is ample financial, professional, and political investment (Sheldon, 1988). Therefore, the selection of textbook for a particular group of learners is an important issue that has to be taken into consideration.

Since the options to select teaching materials may vary from totally free to extremely circumscribed in different situations, "the ability to evaluate them effectively is a very important professional activity for all ELT teachers" (McDonough \& Shaw, 1993, p.63). Moreover, it seems that, for the selection of a suitable textbook, it is important to conduct an evaluation in order to make sure that the textbook is suitable for the students. While a textbook is designed and published for educational purposes, evaluation may be done impressionistically and consists of attempts to forecast whether or not the materials will work, in the sense that the learners will be able to use them without too much difficulty and will enjoy the experience of doing so.

One of the most significant issues in material evaluation is application of multiple intelligence theory. Research studies have shown that the implementation of multiple intelligence is probably to intensify students learning and performance and make students have better mental cognition toward language learning experience (Emig, 1997). As Gardner stated, the execution of MI theory in general educational environments in addition to language learning classrooms has already been strengthened by the speculative discussion influenced by traditional intelligence tests mainly assumed on intelligence as a single ability tradition can hardly account for multi-faceted nature of human 
intelligence (as cited in Andarab, 2014). The consideration of textbooks in the light of MI theory is indispensably beneficial due to the fact that textbooks are the main practical sources of teachers in classroom to transfer the curriculum objectives (Sahragard \& Zaremoayedi, 2009).

However, a quick review of the literature shows that only a very small number of studies to date have been devoted to the investigation of textbook evaluation in the EFL context in the light of MI theory. Moreover, none of them have been considered the students perspectives in this due. More recently, textbook have been analyzed based on MI theory to present quantitative statistics of the included types of intelligences in the "Right Path to English Textbook" (Taase, 2012). Unlike the previous studies, the present study evaluates one of the Iranian Junior High School English Textbooks "Prospect One" from the students' viewpoints based on Bottelho's MI checklist and see to what extent they include all the intelligences in the activities.

Gardner (1993) claimed nine comparatively independent, but interdependent intelligences instead of just a single intelligence named intelligence quotient. He defines the concept of intelligence as the ability to solve problems or fashion products that are of consequence in a particular cultural setting or commodity (Gradner, 1993, p.15). Nevertheless, Gardner claimed that human brain has different areas of intelligences; which includes verbal/linguistic, logical/mathematical, spatial/visual, bodily/kinesthetic, musical, intrapersonal, interpersonal, naturalist, and existential, but individuals differ in using and combination of them.

\section{Literature Review}

\subsection{Role of Textbook in Language Teaching}

Textbooks are one of the supplements among increasingly broad and different teaching materials. They are bound collections of textual and visual material, designed for teaching and learning particular subject (Bourdillon, 1992). Thus, it could be concluded that textbooks are very important in all types of educational institutions all over the world.

Cunningsworth (1984) confirms that no textbook is totally suited with a particular teaching situation. However, the role of the textbook is to be a tool to serve the teachers and learners but not their superior. So the teacher and the material connection is a collaborative relationship which shares common goals to which each side brings its special contribution. In addition, meeting the needs of the learners should be of the main the aims of the textbook.

\subsection{ELT Textbook Evaluation in Iran}

Evaluation is seen as "activity of assembling information to be benefited in making educational decisions" (Genesee \& Upshur, 1999). Evaluation is not merely a process of achieving data, but also a decision-making process. In a wider term, it is entailing assessment, but including other processes as well (Nunan, 1988). These supplemental processes are designed to help in rendering and performing the results of the assessment. The basic purpose of evaluation in school is to bring about quality improvement in education by providing feedback regarding pupils learning, classroom teaching, appropriateness of curriculum and course content.

There are three components of the evaluation process. The first one is the collection of information, while taking into account factors such as students' background, learning processes, and instructional factors. The second component is the interpretation of the information and comparing it with some desired state of affairs, goals, or other information that is relevant to one's decisions. And the third one is the decision-making process about instruction, students, textbooks etc. (Becerra, 2006, P.33).

ELT textbooks investigation has a short history in Iran. Such studies focus on textbook from different perspectives such as analyzing the status of sexism in ESL/EFL textbooks in Iran (Ansari \& Babaei, 2003), investigating the place of culture in ELT textbooks (Aliakbari, 2004), critical discourse analysis framework for textbooks (Keshavarz \& Akbari Malek, 2009), and Bloom's (1956) taxonomy of learning objectives, types of learning objectives represented in Iranian senior high school and pre-university English textbooks (Riazi \& Mossalanejad, 2010).

In a recent study, Taase (2012) studied locally designed ELT textbooks in the light of multiple intelligences theory. Three textbooks (grade 1, 2 \& 3) used in guidance school of Iranian educational system were analyzed using Botelho's (2003) MI checklist, measuring different kinds of intelligences in the activities. The results revealed that verbal/linguistic and visual/spatial intelligences were the most prevalent ones followed by logical/mathematical, interpersonal and intrapersonal in much lower ratios. In addition, bodily/kinesthetic, musical and naturalistic intelligences were not found in any percent. 


\subsection{The Multiple Intelligences Theory}

Psychology continued its point of view about the intelligence around nineteenth century, when the British psychologist, Francis Galtons began his research about humans individual mental abilities. He was interested in classifying human concerning their physical and intellectual abilities. He also believed that intelligence could be inherited and educated people could have their sensorial capacities more sharpened (Gardner 1994). As for understanding the different concepts of intelligences there are different approaches. The most traditional one is called the psychometric view, stating that there is a single intelligence which is often called general intelligence or g-factor. Every human being is born with a particular intelligence or potential intelligence, which is hardly changeable.

However, science started to believe that it would be necessary to observe more complex abilities such as language and abstraction. In the beginning of the twentieth century, the French psychologist Albert Binet began maturing the first intelligence tests in order to measure children's capacities in a way which could foretell whether these children would succeed or fail in school (Oliveira, 2009). This intelligence test was called Intelligence Quotient or "IQ".

However, Gardner (1983) criticizes the way IQ tests measure one's abilities, arguing that our society is "brainwashed to restrict the notion of intelligence to the capacity used in solving logical and linguistic problems." (p.14) Thus, it is possible to claim that Gardner means that intelligence is a wide concept which embodies more than performance in learning. He also claimed that: there are many limitations on the tools of IQ tests and on the use which is made of them. He also says that IQ tests is usually able to foretell success in academic life but weak in other context out of this environment.

Gardner's theory of Multiple Intelligences was originally proposed at Harvard University in 1983. He published his book "Frames of Mind". This theory was revolutionized the concept of intelligences. As mentioned above, he claimed that human capabilities cannot be measured by traditional intelligence tests like the IQ ones. Gardner says that "Multiple Intelligences theory pluralizes the traditional concept." (1993, p.15).

Gardner defines intelligence as a "bio psychological potential of intellectual faculties. That is the ability to solve problem, or to fashion products, that are valued in one or more cultural or community setting" (1993 p.7 and p.37). He stated eight layouts of intelligences in human brain: linguistics, logical- mathematics, visual-spatial, interpersonal, intrapersonal, musical, bodily-kinesthetic and naturalist. (Armstrong, 2001; Gardner, 1993), and in 1995, having focused new data about the criteria, he added up the naturalistic one. Human different and individual abilities can be considered as evidence that multiple intelligences exist. Multiple intelligences can be utilized either individually or as combination of two or more intelligences. According to Gardner, each person has all of the eight intelligence combined in different ways forming what he calls the "intelligence profile" (Gardner, 1994, p.7).

\subsection{Multiple Intelligences Theory and Textbooks}

Snider (2001) surveyed 10 German textbooks and at last suggested some activities which enhance intelligences other than verbal/linguistic intelligence. Palmberg (2001) clarified the intelligences that were predominant or less common, and also analyzed the manifestations of each intelligence in an English book. Palmberg (2002) in his thesis study presented the evaluation of textbooks by student and teachers in order to clarify intelligence profile in the activities. Kirkgöz (2010) investigated locally-published ELT textbooks in Turkey and found that naturalistic intelligence was the least type in Turkish textbook.

In Iranian context, Razmjoo and Jozaghi (2009) worked on Top-notch series considering multiple intelligences theory. To this end, Top-notch is predominant by verbal intelligence followed by the visual, logical, musical, interpersonal, bodily, and intrapersonal one while it is poor in representing natural and existential intelligences. Recently, Taase (2012) analyzed ELT textbooks used in guidance school of Iranian educational system to measure the extent to which Multiple Intelligence Theory had been considered in the provided activities. The result shows that verbal/ linguistic and visual/spatial were the most predominant intelligences in the English junior high school textbooks. However, bodily/kinesthetic, musical, and naturalistic intelligences were the less predominant ones.

From the educational view of this theory, Gardner also proposes that there is a large necessity for educators to estimate precisely the intelligence profile of the individual learner. (Gardner1993). He asserts that it is very important to recognize the learners' strengths and weaknesses, and also it is even more important to know the learner's deficiencies which could predict learning difficulties and also provide the teacher and learner a tool to cope with that. Gardner believes that the intelligence profiles are changeable during one's life and that through education and instruction it would be possible to intensify an individual's shortcomings (Gardner, 1994).

In addition, multiple intelligences could not only supply teachers with more options in teaching and evaluation methods, but also enable students to present what they have learned in many various ways. Another view, then, is to 
use multiple intelligences teaching as a resource for students to examine their intelligence strengths. Since the varied style of learning recommended by multiple intelligences theory can reveal the strengths and weaknesses of students, it helps the teachers understand each student better and provide specific support where necessary. The third view is to aid students in acting better in their areas of strength and to study the learning difference (Yang, 2008). According to multiple intelligences theory, schools should employ different approaches to monitor the students' problem-solving skills, performance, and characteristics' in long-term. They should also appraise the students' prevalent level from different perspectives.

Considering the learner's different abilities and intelligences should be proceed in educational systems include language courses, language institutes, schools, and any other places where language is taught. Botelho (2003) states that many schools in the US have changed their curriculum in order to apply the theory. In other education environment around the world, private and public schools started to change their curriculums based on human mental abilities. Teachers considered the intelligence profile of the course books they choose in order to evaluate how they fit their learners (Botelho, 2003). They chose their textbooks based on learners' different purposes and needs.

However, it is arguable that it cannot be easy for teacher to apply the theory of multiple intelligences inside the classroom since it needs extra activities beside all other which every teachers have in their classrooms. If a teacher decides to apply MI theory in the class, it would be a must for him/her to pay attention to the students' profile and prepare individualized task in order to meet students' needs. Gardner recognizes the difficulties teachers might face but he debate that it is necessary to work on the individual differences emphasizing the importance of it.

Moreover, one of the biggest problems for teachers is that the course books and other EFL materials have a fix model which cannot be changed by the teachers and they are supposed to use these course books as the basis of their work. In the other hand, using a single frame of course book does not mean that teachers have to obey the same way in their methodologies. We can try to update the methodologies of our course books in order to meet the individual needs and purposes. So teachers play a crucial role while using the course books in their classrooms.

\section{Research Question}

The present study aims at investigating the levels of multiple intelligence in 1st- grade junior high school English textbook from student viewpoints. Therefore, based on the objectives of the study, the following research question was proposed:

From students' view point, to what extent does newly published 1st-grade junior high schools' English textbook include the intelligences based on Botelho's (2003) multiple intelligence checklist?

\section{Methodology}

The present study aimed at analyzing how 1st-grade Junior high schools' English textbooks respond to MI theory from students' perceptions and to what extent they include all the intelligences in the activities provided. Each activity is related to one particular intelligence, however, the students answered the questioner unconsciously without knowing anything about multiple intelligences theory.

\subsection{Participants}

A total of 165 male and female students participated in the present study. They were from Tehran, Gorgan, and Karaj's Public, Private, and Gifted schools. Furthermore, the participants included both male and female students. The ratio of male to female participants, however, was not controlled.

\subsection{Instruments}

This study aimed to find the level of multiple intelligences in the 1st- grade junior high school English textbook, the formal written material published and printed by the Iran's Ministry of Education entitled "Prospect One" which is taught in the first grade Iranian Junior high schools since 2013.

Thus two types of instruments were employed.

\subsubsection{Prospect one}

This book is the newly edited version of English textbook for 1st- grade junior high school students in Iran. It is the most recently compiled textbook published in 2013 including 8 lessons and 76 pages, four reviews and a photo dictionary at the end of the book in A4 format. This book is different from the previous version for its different font 
colors and various shapes and pictures. The lessons follow a general framework in all units starting with "Conversation" followed by two "Practices", "Listening and Reading", "Writing and Speaking", "Your Conversation" at the end of the lesson, and "Review" part after each two lessons, aiming at consolidating the material. At the end of the book, a photo dictionary presents all the new words included in the book helping learners for better comprehension and understanding.

\subsubsection{Multiple Intelligences Evaluation Checklist}

In order to measure the level of multiple intelligences from students' view point, the researcher employed the checklist developed by Botelho (2003) which involves 50 items and eight sections in order to measure different intelligences. For example, verbal linguistic intelligence is defined as the ability to use words effectively both orally and in written form. The range of activities related to this intelligence include reading books, listening to the audios, writing, note taking, remembering and memorizing the words and etc. This checklist was translated by the researcher since there was no suitable research tool in the native language which could meet the objectives of the present study. The result of this checklist determined the level of satisfaction of students from the level of intelligences provided in the activities in each book.

The selected checklist was initially developed in English by Botelho (2003), which was translated into Persian. The first draft of translated checklist was revised twice after consultations with five experts of applied linguistics then, two reviewers (the researcher herself, as a Persian native speaker studying TEFL and an English teacher with seven years of teaching experience) examined the accuracy, suitability, and appropriateness of the translations. Then, in order to avoid bias, the revised version was given to five Junior high school teachers to judge whether the checklist was a true instrument for measurement considering content validity or not.

The translated version was piloted in a representative sample include 12 students in the pilot stage, i.e. The pilot testing revealed that the students did not experience any kind of difficulties in understanding and completing the items of checklist. Also, it was essential to feel confident about the reliability of the English checklist. For the reliability of the checklist, the researcher used Cronbach's alpha coefficient and the reliability index was estimated to be 0.89 .

\subsubsection{Design and Data Analysis}

To answer the research questions put forward in the study, descriptive analyses were performed using SPSS 16 software. The descriptive statistics such as mean, standard deviation, and range were calculated in order to examine the central tendencies and dispersion. The assigned checklist indicated the subjects' attitudes and point of view toward the materials they were exposed to; the results revealed to what extent the students are satisfied with the intelligences which are provided in the activities, however, revealed students attitude toward MI theory in terms of subjects' level of interest, enthusiasm, activity, persistence, concentration, and enjoyment.

\subsubsection{Procedure}

First, the students filled the checklist to determine the level of multiple intelligences provided in the activities. The students had to check the question and respond if they were; agree, somewhere between, or disagree with each item mentioned according to the activities of their English textbook. Once the required data was collected by means of the checklist, the completed checklist had to be quantified for descriptive analysis.

\section{Results}

Aiming at answering the research question, the 50 items checklist was arranged attentively. As mentioned, all the participants expressed the degree of their agreement or disagreement on three point Likert scale ranging from 0 for "disagree", to 2, for : agree".

Descriptive statistics also used to investigate the level of multiple intelligence throughout the textbook "Prospect One" considering students' viewpoints. Descriptive statistics including frequency counts and percent of each intelligence were calculated for the research question using SPSS 16. Table 1 shows the mean and standard deviation of each of the intelligences in the textbook "Prospect 1". 
Table 1. Descriptive Statistics on Multiple Intelligences, 1st- Grade

\begin{tabular}{lccc}
\hline & $\mathrm{N}$ & Mean & Std. Deviation \\
\hline Verbal & 165 & 13.8788 & 4.01033 \\
Visual & 165 & 9.1939 & 4.05586 \\
Intrapersonal & 165 & 6.2485 & 2.79242 \\
Interpersonal & 165 & 6.2242 & 2.89733 \\
Bodily & 165 & 6.182 & 3.81344 \\
Logical & 165 & 4.1879 & 2.36485 \\
Musical & 165 & 3.4667 & 2.92703 \\
Naturalistic & 165 & 1.3636 & 1.34840 \\
\hline
\end{tabular}

As revealed by table 1, the profile of the book Prospect 1, from students' perspective was dominated by verbal/ linguistic intelligence with the mean score of 13.8. More than half of the students believed that the range of the occurrence of verbal/linguistic intelligence in "Prospect One" is "Mid" (52.72\%) followed by "High" (39.39\%) and the least preferred alternative is "Low" with the percent of $(7.87 \%$.). It seems that most of the students agree upon the widespread use of verbal/linguistic intelligence in this textbook. Three students scored verbal/ linguistic intelligence completely, 87 out of 165 students scored "Mid" followed by 65 students who scored "High" and 13 students scored "Low" in this part.

The second preferred intelligence is visual with the mean of 9.1. The most frequently alternative of visual/ spatial intelligence in Prospect One is "Mid" from students' viewpoint. About half of the students (49.9\%) rated visual/ spatial intelligence "Mid" consecutively, $28.48 \%$ of the students scored "Low". like logical intelligence, "High" is less preferred alternative from students' perspectives with the percent of $22.42 \%$. Among the participants, 81 of them scored "Mid" which is the most predominant choice. None of the students scored visual/ spatial intelligence fully (18) which is the highest possible score. Totally, 47 students selected "Low", followed by 37 students "High". Like Verbal intelligence, students accepted the high occurrence of Visual/ spatial intelligence in "Prospect One".

The next three types of intelligences included intrapersonal (6.24), interpersonal (6.22) and bodily kinesthetic (6.01). As for intrapersonal intelligence, More than half of students scored "Low" (50.9\%) and "Mid" (47.87\%) respectively. Finally, just two students rated "High" (1.21\%). It should be noted that, only one student rated interpersonal intelligence completely (18). As observed, 84 of students scored "Low", followed by 79 students who rated "Mid". At last, only two students scored "High". Like musical intelligences students mostly accept the occurrence of intrapersonal intelligence in Prospect 1 is not satisfactory.

Regarding interpersonal intelligence, most of the students scored "High" (44.84\%) and "Mid" (43.63\%) respectively. Finally, 19 students rated "Low" (11.51\%). It should be noted that, 10 students rated interpersonal intelligence completely and that 74 of students scored "High", followed by 72 students who rated "Mid, 72 students scored "Mid". Like intrapersonal and bodily/ kinesthetic intelligences students accepted the occurrence of interpersonal intelligence in "Prospect One".

The next category was related to bodily/ kinesthetic intelligence. The most frequent alternative in the checklist is "Low" (41.81\%) followed by "Mid" (36.36\%). Finally, a few students $(21.81 \%)$ answered "High". The significant difference between bodily/kinesthetic intelligence and other types is that "Low" alternative is mostly preferred. However, two students scored it fully (14). Among the students, 69 students scored "Low" followed by 60 students who scored "Mid", 36 students scored "High". Finally, 11 students rated the occurrence of bodily, kinesthetic intelligence in Prospect 1. It can be said that students did not accept the highly distributed frequency occurrence of bodily/kinesthetic intelligence.

Then, logical mathematical intelligence with the mean of 4.1 and musical intelligence with the mean of 3.4 were preferred by students. Logical mathematical intelligence is the sixth predominant intelligence based on students' answers. Like verbal/linguistic intelligence, most of the students scored "Mid" (42.42\%), followed by "Low" (36.96\%). Finally, a meager portion of students (20.60\%) answered "High". Unlike verbal/linguistic intelligence, no students scored logical/ mathematical intelligence fully (10) denoting that they did not score all five questions of this part "High" (2). Among 165 students, 70 students scored "Mid" followed by 61 students who scored "Low", 34 students scored "High". It can be said that students believe that occurrence of logical/ mathematical intelligence was not sufficient in "Prospect One".

As for musical intelligence, students scored "Mid" more than other alternatives in musical intelligence. More than half of the students $(50.9 \%)$ rated musical intelligence "Low" followed by $30.90 \%$ of the students who scored "Mid". 
At last, $18.18 \%$ of the students scored "High". Among the students, 84 of them scored "Low" which is the most predominant alternative. Only three students scored musical intelligence fully (10) which is the highest possible score. Totally, 51 students selected "High" (3-6). Like logical intelligence, students recognized the less frequency occurrence of musical intelligence in "Prospect 1 ".

Finally, naturalistic intelligence was the least preferred type with the mean of 1.3. The application of naturalistic intelligence from students' perspective is similar to from musical and intrapersonal intelligences; so that, $57.57 \%$ of the students rated "Low" followed by "Mid" (33.33\%). In this type of intelligence a meager portion of students selected "High" alternative (9.09\%). In this part, there were two questions in which seven students scored naturalistic intelligence completely (4). It is shown that 95 students rated "Low", 55 students "Mid", and 15 "High". At the end, it is observed that musical and naturalistic intelligences are the least preferred type of intelligences from students" viewpoint (to see a more tangible view see figure 1).

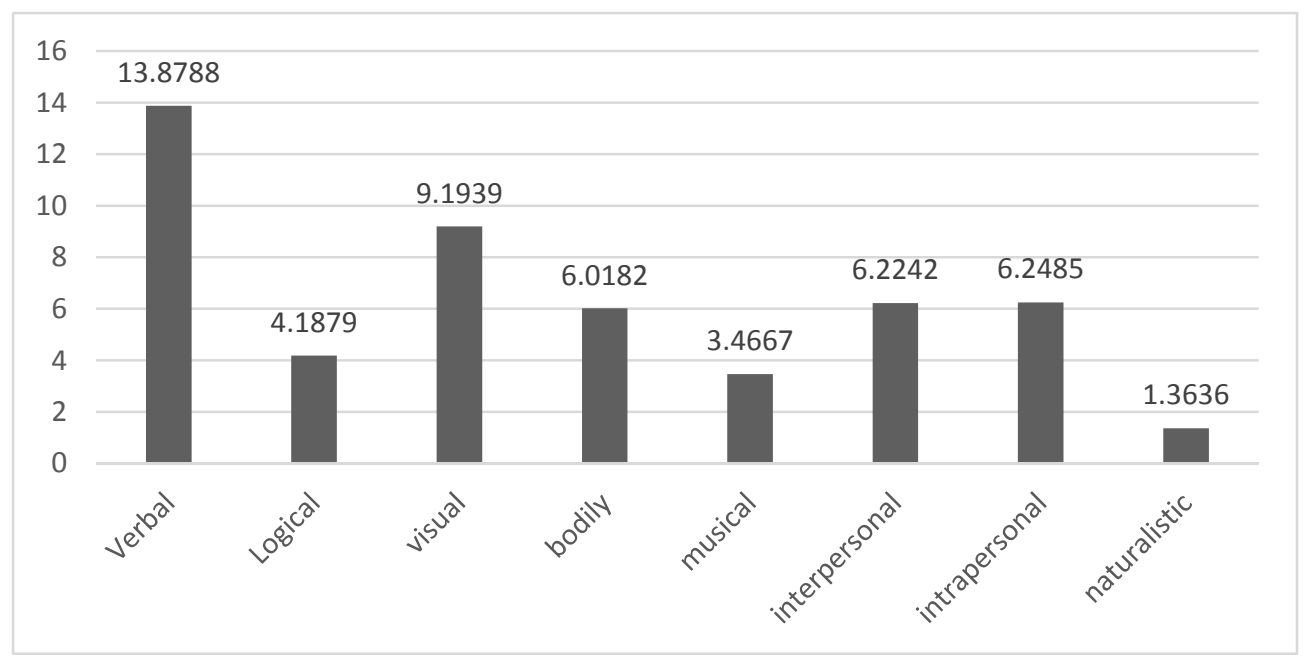

Figure 1. The Mean of Multiple Intelligences of Prospect 1

\section{Discussion}

The aim of the present study was to see to what extent newly published 1st-grade junior high school English textbook included each of the intelligences based on Botelho's (2003) multiple intelligences checklist from the students' viewpoint. The data gathered from each section of the checklist was analyzed and interpreted in detail. As mentioned above, verbal/ linguistics were the most predominant intelligence which is in agreement with all the previous researches on textbook evaluation based on MI theory like Botelho (2003), Kirkgöz (2010), Razmjoo and Jozaghi (2009), Taase $(2012,2014)$. Verbal/ linguistic intelligence is the main part of the previous theory of intelligence (IQ) and the reason that it is presented highly in the textbooks is that all other intelligences are stated through language and this type is mixed with other intelligences in exercises and activities. As the book is mostly focuses on tenses, grammar practices, individual activities, conversation sections, pair and group works, putting some words on the special places or tables, showing some verbs and nouns through movements, and finding the place of something inside the map, and also the activities which force students to active their prior vocabulary knowledge, So, the state of existing verbal linguistic, visual spatial, intrapersonal, interpersonal, and bodily kinesthetic intelligences are expected.

Logical/mathematical was the sixth predominant intelligence from students' perception in Prospect 1 as there are a few science thinking, creation, calculation, solving activities and games in the provided activities. The result of this type of intelligence is the same as Kirkgöz (2010) which logical/ mathematical intelligence was the sixth frequently used type; it was the fifth mostly occurred intelligence in "Top-Notch Series" (Razmjoo \& Jozaghi 2009); and the forth dominantly catered for intelligence in "Pacesetter Series" (Taase, 2014).

Musical and naturalistic intelligences were the two least dominant intelligences type in the list from the student' perception which is in sharp contrast to previous studies. Musical intelligence, in most of the previous studies was the fifth type in Botelho (2003), Kirkgöz (2010), and Taase (2014). The reason for less occurrence of musical intelligence is the lack of rhythm, music, singing songs, and activities which are depend on the music. As for naturalistic intelligence which is the last predominant intelligence in the Prospect 1 from students' viewpoints, there are not any 
activities related to the natural world such as talking about environment issues, classifying and categorizing birds, animals, and plants.

These results to some extent overlap with the result of Taase (2012). The results obtained from the questionnaire support these results since verbal/linguistic and visual/spatial were the most predominant intelligences in those books. However, musical, and naturalistic intelligences were the least predominant ones.

Finally, based on the presented results, the researcher came to the conclusion that some intelligence such as verbal, visual, interpersonal, intrapersonal, and bodily were applied satisfactorily from students' perspective. However, there is a need for more diversity in the other remained intelligences. One of the most worthwhile results of this study is the absence of naturalistic and musical intelligence in the textbook profile. According to Botelho (2003), in order to include the less common intelligences in one's teaching, the activities in a textbook can be exploited in another manner. Another possibility is to supplement textbooks with extra materials or activities. These changes do not merely involve the less common intelligences but also aid to balance the type of intelligences in teaching in order to fit learners' profile. (Botelho, 2003).

It should be noted that each intelligence is presented through multiple ways (Gardner, 1983). For example, verbal/linguistic can be presented through hearing and seeing words, speaking, reading, writing, discussing and debating and etc., visual spatial through Working with pictures and colors, visualizing, using the mind's eye, drawing and bodily/kinesthetic intelligence can be presented through Athletics, dancing, crafts, using tools, acting, Moving around, touching and talking and using body language.

Due to the important role of textbooks in educational curriculum of Iran, the finding of the present study provides information to textbook designers as well as teachers. Applying multiple intelligences in the textbooks in addition to classrooms curriculum can provide teachers with opportunities to look differently at the curriculum, instruction and assessment.

\section{Conclusion}

As mentioned, the findings of this study were only partially supported by the experimental data and descriptive analysis. The purpose of the present study was to investigate, evaluate and analyze English textbook "Prospect One" of Iranian junior high school in order to illustrate the students' perceptions regarding the application of MI theory. Furthermore, this study intends to explain the educational value, significance and suitability of the 1st-grade English book in Iranian junior high schools in the light of multiple intelligence. For this purpose, the perceptions of students towards the book were taken into account in terms of Botelho's (2003) multiple intelligence evaluation checklist which includes eight intelligences.

The results showed that in the newly designed English textbook "Prospect One" verbal linguistic intelligence was the most dominant intelligence followed by visual, intrapersonal and interpersonal intelligences. The finding obtained from the descriptive analysis revealed that students were satisfied with the efficient existence of verbal and visual intelligences and somehow satisfied with intrapersonal and interpersonal ones. The next predominant intelligences were bodily kinesthetic as well as logical intelligence which were somehow satisfactory from students' attitude. The last point in this regard is students' dissatisfaction in musical and naturalistic intelligences which were the least predominant intelligences in the category.

On the whole, the conclusion can be drawn from the present study is that from students' perspective, "Prospect One" is successful in most of elements which are included in the Botelho's (2003) checklist except in musical as well as naturalistic intelligences. In other words, most of students' participated in the study insisted on their positive perceptions of this book and believed that this book provides students' needs in terms of considering the multiple intelligence theory.

\section{References}

Aliakbari, R. (2004). Multiple intelligences and language learning strategies: Investigating possible relations. System, 36, 141-155. http://dx.doi.org/10.1016/j.system.2007.09.008

Andarab, M. (2014). Let's replace words with pictures: The role of pictures and spatial intelligence in learning. Theory and Practice in Language Studies, 4(2), 244-254. http://dx.doi.org/10.4304/tpls.4.2.244-254

Ansari, H. \& Babaei, E. (2003). Universal characteristics of EFL/ESL textbooks: A step towards systematic textbook 
evaluation. The Internet TESL Journal, 5(2), 24-31.

Armstrong, T. (2001). Multiple intelligences in the classroom. Alexandria, VA: Association for Supervision and Curriculum Development.

Becerra, N. (2006). The relationship between the primary teachers' teaching strategies and their strengths in multiple intelligences. Procardia Social and Behavioral Sciences, 1, 708-712.

Bloom, B. S. (1956). Taxonomy of educational objectives: The classification of educational goals: Handbook I, cognitive domain. New York: Longman.

Botelho, M. R. (2003). Multiple Intelligences Theory in English Language Teaching: An Analysis of Current Textbooks, Materials and Teachers' Perceptions. Doctoral thesis. Retrieved April 22, 2013, from Ohio University: http://drc.ohiolink.edu/handle

Bourdillon, H. (1992). History and social studies: Methodologies of textbook analysis. Amesterdam: Swets and Zeitlinger.

Cunningsworth, A. (1984). Evaluating and selecting EFL Teaching Material. London: Heinemann.

Emig, V. B. (1997). A multiple intelligences inventory. Educational Leadership, 55(1), 47-50.

Gardner, H. (1993). Frames of mind: The theory of multiple intelligences. London: Fontana Press.

Gardner, H. (1994). Multiple intelligences: The theory in practice. New York: Basic Books.

Genesee, F., \& Upshur, J. A. (1999). Classroom-based evaluation in second language education. Cambridge: Cambridge University Press.

Keshavarz, M., \& Akbari Malek, L. (2009). Critical discourse analysis of ELT textbooks. The Iranian EFL Journal, 5(2), 6-19.

Krkgöz, Y. (2010). Catering for multiple intelligences in locally-published ELT textbooks in Turkey. Procardia Social and Behavioral Sciences, 3(1), 127-130. http://dx.doi.org/10.1016/j.sbspro.2010.07.023

McDonough, J., \& C. Shaw. (1993). Materials and methods in ELT: A teacher's guide. London: Blackwell.

Nunan, D. (1988). The learner-centered curriculum (8th Ed). Cambridge: Cambridge University Press.

Oliveira, C. L. D. (2009). Course books and multiple intelligence theory: An analysis. Porto Alerge, 2(4), 1-58

Palmberg, R. (2001). Catering for multiple intelligences in EFL course books. HLT Magazine, 4(1), 46-49.

Palmberg, R. (2002). Catering for multiple intelligence in EFL coursebook. Retrieved December 9, 2012 from HLT Magazine http://www.hltmag.co.uk/jan02/sart6.htm

Razmjoo, S. A., \& Jozaghi, Z. (2009). The representation of multiple intelligences types in the Top-notch series: A textbook evaluation. Journal of Pan-Pacific Association of Applied Linguistics, 14(2), 59- 84.

Riazi, A. M. (2003). What textbook evaluation schemes tell us? A study of the textbook evaluation schemes of three decades. In W.A. Renanda. (Eds.), Methodology and materials design in language teaching, (pp.52-68). Singapore: Seameo Regional Center.

Riazi, A. M., \& Mosallanejad, N. (2010). Evaluation of learning objectives in Iranian high-school and pre-university English textbooks using Bloom's taxonomy. TESL EJ, 13(4), 1-16.

Sahragard, R., Rahimi, A., \& Zaremoayedi, I. (2009). An in-depth evaluation of Interchange Series (3rd ed.). Porta Linguarum. 12(2), 37-54.

Sheldon, L. (1988). Evaluating ELT textbooks and materials. ELT Journal, 42(2), 237-246. http://dx.doi.org/10.1093/elt/42.4.237

Snider, D. P. (2001). Multiple intelligences theory and foreign language teaching. Doctoral dissertation, University of Utah, Unites States.

Taase, Y. (2012). Multiple intelligences theory and Iranian textbooks: An analysis. Journal of Pan-Pacific Association of Applied Linguistics, 16(1), 73-82.

Yang, M. (2008). Context-aware and attentional visual object tracking. Doctoral dissertation, Northwestern University, USA. 